\title{
Alterations in the Expression of the Apurinic/Apyrimidinic Endonuclease-1/Redox Factor-1 (APE/Ref-1) and DNA Damage in the Caudal Region of Acute and Chronic Spinal Cord Injured Rats Treated by Embryonic Neural Stem Cells
}

\author{
T. DAGCI ${ }^{1,3}$, G. ARMAGAN ${ }^{2}$, S. KONYALIOGLU ${ }^{2}$, A. YALCIN ${ }^{2}$ \\ ${ }^{1}$ Department of Physiology, School of Medicine, ${ }^{2}$ Department of Biochemistry, Faculty of \\ Pharmacy, ${ }^{3}$ Center for Brain Research, Ege University, Bornova-Izmir, Turkey
}

Received September 4, 2007

Accepted April 9, 2008

On-line July 18, 2008

\section{Summary}

The oxidative mechanisms of injury-induced damage of neurons within the spinal cord are not very well understood. We used a model of T8-T9 spinal cord injury (SCI) in the rat to induce neuronal degeneration. In this spinal cord injury model, unilateral avulsion of the spinal cord causes oxidative stress of neurons. We tested the hypothesis that apurinic/apyrimidinic endonuclease (or redox effector factor-1, APE/Ref-1) regulates this neuronal oxidation mechanism in the spinal cord region caudal to the lesion, and that DNA damage is an early upstream signal. The embryonic neural stem cell therapy significantly decreased DNAdamage levels in both study groups - acutely (followed up to 7 days after SCI), and chronically (followed up to 28 days after $\mathrm{SCI}$ ) injured animals. Meanwhile, mRNA levels of APE/Ref-1 significantly increased after embryonic neural stem cell therapy in acutely and chronically injured animals when compared to acute and chronic sham groups. Our data has demonstrated that an increase of APE/Ref-1 mRNA levels in the caudal region of spinal cord strongly correlated with DNA damage after traumatic spinal cord injury. We suggest that DNA damage can be observed both in lesional and caudal regions of the acutely and chronically injured groups, but DNA damage is reduced with embryonic neural stem cell therapy.

\section{Key words}

Spinal cord injury • Stem cell transplantation • DNA damage • APE protein $\bullet$ Ref-1 protein

\section{Corresponding author}

T. Dagci, Center for Brain Research, Ege University, 35100, Bornova-Izmir, Turkey. E-mail: taner.dagci@ege.edu.tr

\section{Introduction}

Traumatic injury to the spinal cord triggers several secondary effects which play a major role in biochemical and pathological changes in the spinal cord tissue. The enhanced production of reactive oxygen species (ROS) during spinal cord injury (SCI) appears to play an important role in neuronal cell death and neurological dysfunction (Vaziri et al. 2004). ROSinduced oxidative DNA damage is believed to be a major cause of these kinds of lesions (Azbill et al. 1997). As oxidatively modified DNA bases have mutagenic potential, their accumulation with time might be a major cause of the physiological changes associated with SCI. By spontaneous depurination of DNA about 10.000 apurinic sites per day per cell are generated (Lindahl et al. 1972). Base modifications occur endogenously or are the result of environmental mutagens, in particular alkylating compounds or ROS. There are multiple repair pathways to excise oxidative base modifications and prevent their incorporation into DNA (Bohr et al. 1999). The DNA repair enzyme, apurinic/apyrimidinic endonuclease (or redox effector factor-1, APE/Ref-1), is involved in base excision repair of apurinic/apyrimidinic sites after oxidative DNA damage. The DNA repair enzyme apurinic/apyrimidinic endonuclease/redox factor1 (APE/Ref-1) is a multifunctional protein involved in both the repair of oxidative and alkylating DNA damage and the regulation of gene expression. First recognized as a major APE, this enzyme catalyzes the cleavage of the 
phosphodiester either $5^{\prime}$ or $3^{\prime}$ to an apurinic/apyrimidinic site (Kawase et al. 1999). Apurinic sites are both mutagenic and cytotoxic (Loeb et al. 1986) and are enzymatically repaired by APE. Human APE/Ref-1 has been reported to be inducible by oxidative stress (Ramana et al. 1998) and has been shown to affect cellular susceptibility to different types of genotoxic agents including oxidative compounds. This strongly indicates that APE/Ref-1 is part of an adaptive cellular response mechanism to oxidative stress. With the use of experimental SCI models in the past few years, the effectiveness of various treatment regimens such as receptor blockers, physiologic antagonists, inhibitors of biosynthetic pathways, and membrane-stabilizing drugs have been investigated (Bambakidis et al. 2005). Embryonic neural stem cells (ENSCs), which exist in various regions of the CNS throughout the mammalian lifespan, can be expanded and induced to differentiate into neurons and glia in vitro and in vivo. Because of these properties, there has been an increasing interest in the identification and characterization of ENSCs and neural progenitor cells both for basic developmental biology studies and for therapeutic applications to the damaged spinal cord (Schultz 2005).

Our aim was to show the changes in the expression levels of APE/Ref- 1 in caudal region of spinal cord-injured rats during acute and chronic period. Singlecell gel electrophoresis (comet assay) procedure was also used to measure molecular changes in caudal region of spinal cord neurons during the progression of oxidative stress. The second aim of this study was to show the changes in APE/Ref-1 expression and DNA damage in caudal region of acute and chronic spinal cord-injured rats after ENSC treatment.

\section{Methods}

Thirty adult, female Sprague-Dawley rats weighing between $250-270 \mathrm{~g}$ were included in the study. The animals were randomly separated into 6 groups. Group 1: Sham (chronic group) (n=5), Group 2: Spinal cord injury (SCI) only (chronic group) $(\mathrm{n}=5)$, Group 3: SCI followed by ENSCs application into the lesion site 9 days after hemisection which has been followed up 28 days after the operation (chronic period) $(\mathrm{n}=5)$, Group 4: Sham (acute period) ( $\mathrm{n}=5)$, Group 5: $\mathrm{SCI}$ only (acute period) ( $\mathrm{n}=5)$, and Group 6: SCI followed by ENSC application into the lesion site 9 days after hemisection which has been followed up to 7 days after the operation (acute period) $(\mathrm{n}=5)$.

The study was approved by the Local Ethics Committee of the Ege University Hospital and was carried out in the Animal Research Laboratory of Ege University, School of Medicine, Izmir, Turkey. All procedures conformed to the recommendations of the Declaration of Helsinki on care and use of animals. All animals were kept in well ventilated, humidified, and temperature-controlled rooms with 12/12-h light/dark cycle.

\section{Spinal Cord Injury}

Following anesthesia with intraperitoneal ketamine $(50 \mathrm{mg} / \mathrm{kg})$ and xylazine $(5 \mathrm{mg} / \mathrm{kg})$, lowest ribs and the vertebrae they attach to were identified. The back musculature was excised and a laminectomy was performed at the T8/T9 level. Dura was incised above the dorsal root entry zone. Microscissor cuts were created at the rostral and caudal extents of the injury. Aspiration was used to selectively ablate only the lateral white matter tracts and a minimal portion of the dorsal and ventral gray matter. However, the dorsal columns and central canal were untouched. Once hemostasis was achieved, NRP/GRP cells in collagen matrix were implanted into the injury cavity. The cell/matrix mixture completely filled the cavities, and in each case $\sim 1 \times 10^{6}$ cells were grafted into the injury site. The dura was closed with 9-0 suture, muscle was reapposed and the skin closed with wound clips. Body temperature was kept at $37{ }^{\circ} \mathrm{C}$ during and within the first $24 \mathrm{~h}$ after the operation using a heat plate. Intramuscular ampicillin at a dose of $150 \mathrm{mg} / \mathrm{kg}$ was used for prophylaxy for the next 7 days. Each rat was housed individually in a cage with a dry floor and material that prevents formation of decubitus ulcers. The positions of the rats were changed twice a day in the first week. In the first two weeks, the bladder was emptied every $8 \mathrm{~h}$ until reflex micturition was restored and twice daily afterwards. Animals were immunosuppressed by subcutaneous administration of cyclosporine A $(10 \mathrm{mg} / \mathrm{kg})$ daily, beginning three days before grafting and continuously until sacrifice.

\section{Locomotor function}

Locomotor function was assessed blindly by using an open-field locomotor test and scored according to the Basso, Beattie and Bresnahan (BBB) rank scale (Basso et al. 1995). The BBB procedure uses an ordinal nonlinear 21-point scale from 0 (no observable movements) to 21 (normal locomotion) for locomotor 
evaluation. This test is used to assess the state of contusion injury, showing deficits and partial recovery.

Preparation of embryonic neuronal stem cells for transplantation

ENSCs (NRP and GRP-Neuronal and glial restricted precursors) were isolated from embryonic day 13.5 rats. The preparation of NRPs and GRPs has been described previously (Han et al. 2002, Lepore et al. 2005). Briefly, embryos were isolated in DMEM/F-12. Trunk segments were incubated in collagenase type I/dispase II/Hanks balanced salt solution (HBSS) solution for $8 \mathrm{~min}$ at room temperature to remove meninges from the cords. Cords were dissociated using a $0.05 \%$ trypsin/EDTA (Invitrogen) solution for $20 \mathrm{~min}$ at $37{ }^{\circ} \mathrm{C}$. Cells were then plated in complete medium [(DMEM/F12, BSA, B27, basic FGF, penicillin-streptomycin, N2, and neurotrophin-3] (Sigma, St. Louis, MO, USA) on poly-L-lysine and laminin-coated dishes. After dissection, NRP and GRP were co-cultured for 5-10 day in the complete medium to generate a mixed population for grafting. Previous studies (Lepore et al. 2004, 2005) verified that these cultures contained only precursors and were devoid of multipotent stem cells and mature cell types. NRPs and GRPs were dissociated from culture flasks using $0.05 \%$ trypsin/EDTA, washed, and resuspended at a concentration of 100000 cells $/ \mu 1$ (in basal media) for transplantation. Cells were placed on ice throughout the grafting session and grafted in NRP/GRP (1:3). After the completion of the grafting session, cell viability was assessed using the trypan blue assay. Viability was always $>90 \%$. The composition of the NRP/GRP cultures, with respect to the absence of mature cells, was verified before grafting by staining for the mature neurons (neural-specific nuclear protein), astrocytes (glial fibrillary acidic protein), and oligodendrocytes (receptor interacting protein). The purity of the culture with respect to lineage-restricted precursors was verified by staining for the immature neural marker nestin, and the ratio of NRP to GRP was determined by their corresponding markers, embryonic neural cell adhesion molecule and A2B5.

\section{Comet assay}

Caudal region of spinal cord $(1 \mathrm{~cm}$ caudal tissue to the epicenter of injury) was collected in the injury and treatment groups. In the sham-operated control group, a corresponding $2 \mathrm{~cm}$ long segment of the spinal cord was collected. These spinal cord tissue samples were used for the analysis. Comet assay was adapted from the method of Singh et al. (1988). The lesioned region was minced, suspended and chilled with a homogenizing buffer (pH 7.5) containing $0.075 \mathrm{M} \mathrm{NaCl}$ and $0.024 \mathrm{M}$ $\mathrm{Na}_{2}$ EDTA and then homogenized and gently using a Potter type homogenizer. Homogenates were centrifuged at $700 \mathrm{xg}$ for $10 \mathrm{~min}$ at $0{ }^{\circ} \mathrm{C}$ and the precipitates were resuspended in chilled homogenizing buffer. The cell suspension was mixed with $500 \mu$ of LMP agarose in PBS at $37{ }^{\circ} \mathrm{C}$, and $140 \mu \mathrm{l}$ of this mixture was applied onto a frosted glass microscope slide pre-coated with a layer of $1 \%$ NMP agarose $(150 \mu 1)$. After application of a third layer of NMP agarose, the slides were immersed in cold lysing solution $(2.5 \mathrm{M} \mathrm{NaCl}, 100 \mathrm{mM} \mathrm{Na} 2$ EDTA, $10 \mathrm{mM}$ Tris, $1 \% \mathrm{~N}$-sodium lauroyl sarcosinate, $1 \%$ Triton-X-100, $10 \%$ DMSO) for $1 \mathrm{~h}$ at $4{ }^{\circ} \mathrm{C}$. The slides were then placed in an electrophoresis tank, allowing the DNA to unwind for $15 \mathrm{~min}$ in the alkaline solution (300 mM NaOH and $1 \mathrm{mM} \mathrm{Na} \mathrm{NaDTA}_{2}$ ). Electrophoresis was then performed at $300 \mathrm{~mA}$ for $20 \mathrm{~min}$ in the same alkaline solution at room temperature. The slides were neutralized with $0.4 \mathrm{M}$ tris- $\mathrm{HCl}$ buffer $(\mathrm{pH} 7.4)$ and were stained using the silver staining method described by Nadin et al. (2001). The dried microscope slides were covered with a cover-glass prior to analyzing under an Olympus light microscope. The microscope was connected to a charge-coupled device camera and a personal computer-based analysis system (CASP-Comet Analysis Software Program, 1.2.2 Version) to determine the extent of DNA damage after electrophoretic migration of DNA fragments in the agarose gel. Results were expressed as percentage of DNA in the tail (tail\%) or in tail moment [Tail DNA\% x Tail Length (percent of DNA in the tail) $\mathrm{x}$ (tail length)] or tail length (length of the comet tail measured from right border of head area to end of tail in pixels). Three samples per rat were assayed implicating 50 cells per sample. The means \pm S.E.M. of the three samples were calculated for each rat.

\section{$R T-P C R$}

Total RNA was extracted from the lesioned regions using TriTidy $G$ reagent followed by phenolchloroform extraction and isopropanol precipitation (Chomczynski 1993). One $\mu \mathrm{g}$ of total RNA was reversetranscribed at $42{ }^{\circ} \mathrm{C}$ for $1 \mathrm{~h}$ in a $20 \mu \mathrm{l}$ reaction mixture containing mouse Moloney Leukemia virus reverse transcriptase. The cDNA products were amplified for APE/Ref-1 gene expression via PCR with APE/Ref-1 specific primers. The forward primers were 5'-GCCAG 
Table 1. Effect of ENSC therapy on caudal DNA damage comet-Tail-DNA \%, TL and TM scores in sham-controls, chronic and acute SCIrats.

\begin{tabular}{llll}
\hline Sample (n=5) & T-DNA \% & TL & TM \\
\hline Acute sham & $9.93 \pm 0.53$ & $7.33 \pm 2.18$ & $1.33 \pm 0.42$ \\
Acute SCI & $20.12 \pm 3.06^{* *}$ & $14.22 \pm 2.22^{* * *}$ & $4.98 \pm 1.26^{* *}$ \\
Acute SCI+ENSC & $3.47 \pm 0.40^{\dagger \dagger \dagger}$ & $4.75 \pm 0.63^{\dagger \dagger \dagger}$ & $0.38 \pm 0.008^{\dagger \dagger \dagger}$ \\
Chronic sham & $7.575 \pm 0.29$ & $6.75 \pm 1.18$ & $1.18 \pm 0.12$ \\
Chronic SCI & $34.29 \pm 3.75^{* *}$ & $17.50 \pm 1.44^{* * *}$ & $11.64 \pm 2.69^{* * *}$ \\
Chronic SCI+ENSC & $5.07 \pm 2.56^{\dagger \dagger \dagger}$ & $4.67 \pm 1.48^{\dagger \dagger \dagger}$ & $0.46 \pm 0.01^{\dagger \dagger \dagger}$ \\
\hline
\end{tabular}

Data are means \pm S.E.M. Significant differences are indicated as: $* * * p<0.001, * * p<0.01$ vs. sham group; $+\dagger+p<0.001$ vs. SCI group.

AGACCAAGAAGAGTA-3' for APE/Ref-1 and 5'-AGG TCATCCCAGAGCTGAA-3' for glyceraldehyde-3phosphate dehydrogenase (GAPDH). The reverse primers were 5'-AAGGTCATCCCAGAGCTGAA-3' for APE/Ref-1 and 5'-ATGTGAGCCATGAGGTCCAC-3' for GAPDH. Amplification of $2 \mu \mathrm{l}$ RT mixture was carried out using 5.0 $\mu \mathrm{l}$ 10XPCR buffer, $4.0 \mu \mathrm{l} 25 \mathrm{mM}$ $\mathrm{MgCl}_{2}, 1.0 \mu \mathrm{l} 10 \mathrm{mM}$ dNTPs, $1 \mu \mathrm{l}$ of forward and reverse primers $(0.1 \mu \mathrm{g} / \mu \mathrm{l})$ and 5 units Taq DNA polymerase in a total volume of $50 \mu \mathrm{l}$. Cycling parameters were: $5 \mathrm{~min}$ at $94{ }^{\circ} \mathrm{C}, 45 \mathrm{~s}$ at $94{ }^{\circ} \mathrm{C}$ followed by 35 cycles of $30 \mathrm{~s}$ at $60{ }^{\circ} \mathrm{C}$ and $50 \mathrm{~s}$ at $72{ }^{\circ} \mathrm{C}$. The amplified PCR products were analyzed by electrophoresis in $1.7 \%$ agarose gels and visualized under UV illumination after ethidium bromide staining.

\section{Statistics}

Data are expressed as mean \pm S.E.M. or means with $95 \%$ confidence interval (CI), where appropriate. Differences in outcome measures between the groups were examined by Tukey test and Kruskal-Wallis test. $\mathrm{P}<0.05$ value was considered statistically significant. The statistical analysis was carried out using the Statistical Package for Social Sciences (SPSS) Version 13.0 for Windows (SPSS Inc, USA).

\section{Results}

The BBB open-field locomotor scoring was performed to determine the functional outcome of ENSC grafts to injured spinal cords. For all groups, preoperative baseline BBB score was 21. After injury, BBB score dropped to $0-2$ and then gradually recovered. 28 days after hemisection, BBB scores reached a plateau in ENSC groups in acute and chronic groups. In the chronic group (28 days after ENSC transplantation) the animals had an average BBB score of $11.2 \pm 2.9$, which was significantly higher ( $\mathrm{p}<0.01$, Kruskal-Wallis) when compared to the acute group ( 7 days after ENSC transplantation) (4.2 \pm 0.8$)$. There were no significant differences between acutely and chronically spinal cord injured rats $(1.1 \pm 0.4$ and 1.3 \pm 0.6$),(\mathrm{p}>0.05$, Kruskal-Wallis).

Comet assay parameters (including $\mathrm{T} \%$, TL and $\mathrm{TM}$ ) in caudal region of all sham-operated, acute and chronic SCI groups and ENSC therapy rats are shown in Table 1 and Figure 1. In both acute and chronic study groups, T\%, TL and TM levels were significantly higher in the injury groups when compared to the sham-operated groups $(\mathrm{p}<0.001)$. T-DNA \%, TL and TM $(\mathrm{p}<0.001)$ levels decreased in the SCI+ENSC therapy group for both acute and chronic study groups $(\mathrm{p}<0.001)$.

RT-PCR and APE/Ref-1 mRNA expression results are shown in Figures $2 \mathrm{a}$ and $2 \mathrm{~b}$. mRNA levels of APE/Ref- 1 decreased by $43.4 \%$ and increased by $31.8 \%$ in acute SCI and SCI+ENSC therapy groups, respectively in acute study groups and decreased by $32.0 \%$ and increased by $65.1 \%$ in chronic SCI and SCI+ENSC therapy groups in chronic study groups, when compared to the sham-operated group $(\mathrm{p}<0.01)$.

After ENSC therapy, in both acute and chronic SCI groups APE/Ref-1 levels significantly improved $(\mathrm{p}<0.01)$. In addition, chronic ENSC therapy was more effective than the acute $(p<0.05)$ (Fig. $2 b)$.

\section{Discussion}

The most important consequence of SCI is severe nerve injury that results from two mechanisms, primary trauma and secondary damage. The primary trauma induces mechanical compression, bleeding and electrolyte disturbances, which can lead to irreversible nerve injury. The secondary damage is due to edema, 


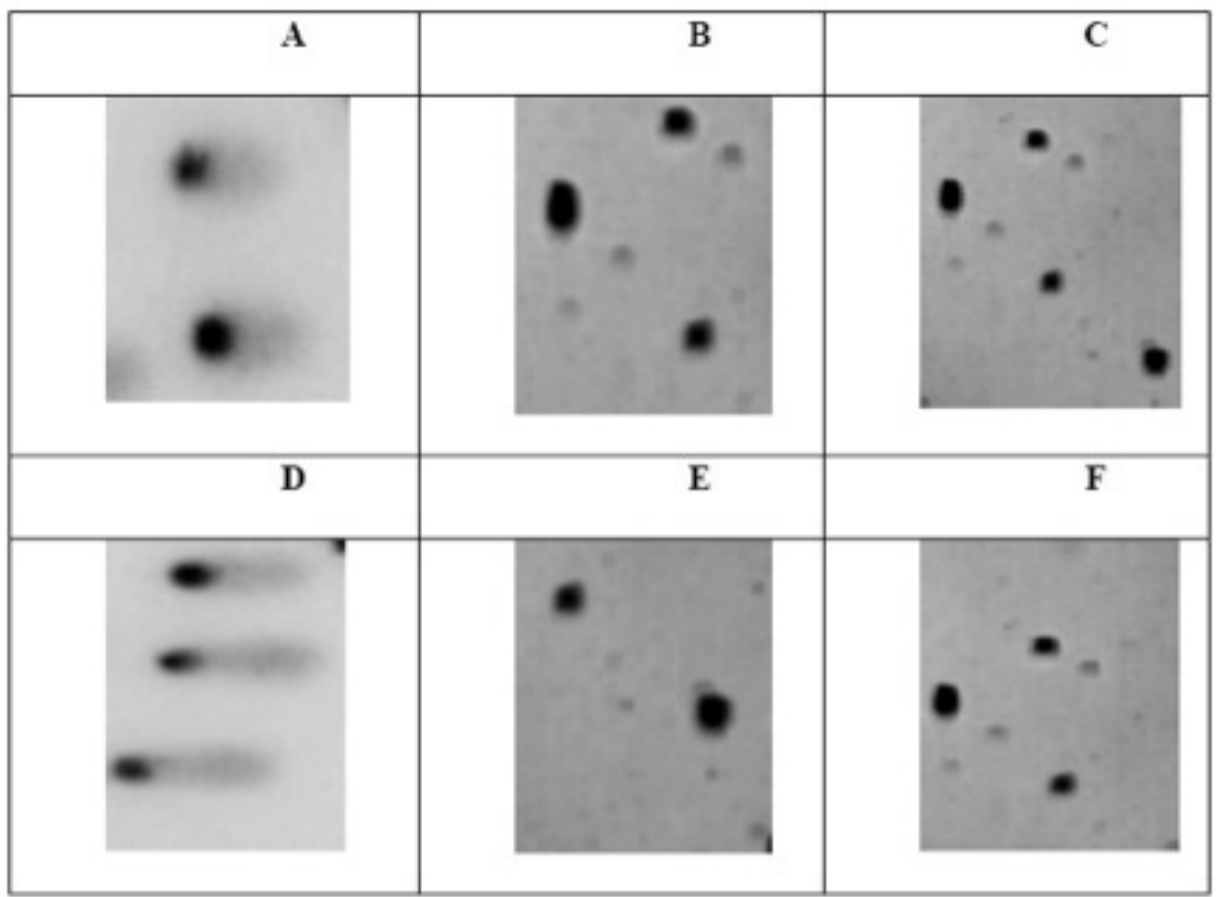

Fig. 1. Typical comets from acute and chronic SCI groups with and without ENSC therapy. Silver staining. Microscope objective X20 A: Acute SCI, B: Acute SCI+ENSC, C: Acute sham group, D: Chronic SCI, E: Chronic SCI+ENSC, F: Chronic sham group. hemorrhage, inflammatory reaction, lipid peroxidative reaction, energy metabolism system disorders, ischemia and oxidative stress, which can give rise to reversible nerve injury. After SCI, the inflammatory cells produce highly reactive oxidizing agents including "free radicals" (Lee et al. 2004, Vaziri et al. 2004).

Reactive oxygen species (ROS) are likely to mediate apoptotic cell death through mitochondrial release of cytochrome $\mathrm{c}$ and activation of caspases after traumatic and ischemic brain injury (Shimazaki 2003, Singh et al. 1988). Several endogenous antioxidant enzymes, such as superoxide dismutase, glutathione peroxidase, and catalase can detoxify ROS. However, overproduction of ROS after injury often exceeds the capacity of these enzymes, causing oxidative stress and subsequent cell death (Singh et al. 1988).

Oxidizing agents attack molecules that are crucial for cell function by modifying their chemical structure. This process is called oxidative damage. Oxidative damage occurs in disorders ranging from slow neurodegenerative diseases like amyotrophic lateral sclerosis (ALS or Lou Gehrig's disease) and Parkinson's disease to acute events like stroke and trauma. Thus, it has been the focus of intensive research. Much of the damage that occurs in the CNS following trauma is due to secondary effects such as glutamate excitotoxicity, $\mathrm{Ca}^{2+}$ overload and oxidative stress, i.e. three mechanisms that in a spiraling interactive cascade lead to neuronal death (Juurlink et al. 1998, Xu et al. 2005).

Focal trauma induces oxidative damage in distinct regions of spinal cord. Several studies showed that the parameters increased during ROS-induced oxidative stress changed not only at the lesion site, but also in regions caudal and rostral to the lesion in the spinal cord (Thornwall et al. 1997). Bao et al. (2004) assessed trauma effects on the expression of APE/Ref-1 expression and DNA damage in the lesioned region of spinal cord. They have shown that DNA damage was increased after SCI, while APE/Ref-1 expression was decreased.

Transplanting genetically modified fibroblasts that secrete BDNF (Brain derived neurotrophic factor) into the lateral funiculus lesion site can support rescue of injured neurons destined to die, regeneration of injured axons, sprouting of spared axons, and ameliorate functional deficits (Kim et al. 2001, Liu et al. 1999, Murray et al. 2002).

Our results showed a decrease in APE/Ref-1 levels and an increase in oxidative DNA damage scores (comet assay) in neuronal nuclei after acute and chronic injury in the caudal section, although DNA damage in other cell groups including glia, infiltrating leucocytes and endothelial cells of vascular walls might also contribute to these changes (Schwab et al. 2005). Nuclear DNA is highly susceptible to oxidative damage because of its proximity to reactive oxygen species and its poor repair mechanisms (Beal 1995). In addition to direct DNA damage, DNA mechanism can also be impaired after SCI. Oxidized DNA normally undergoes base excision repair by APE/Ref-1 (Chopp et al. 1996) and milder forms of brain injury result in an increased expression of repair enzymes 
(a)

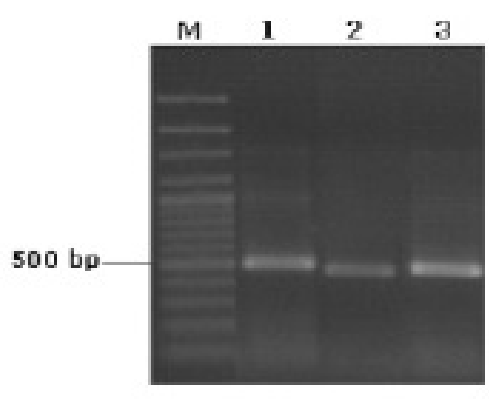

GAPDH

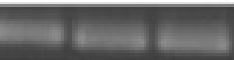

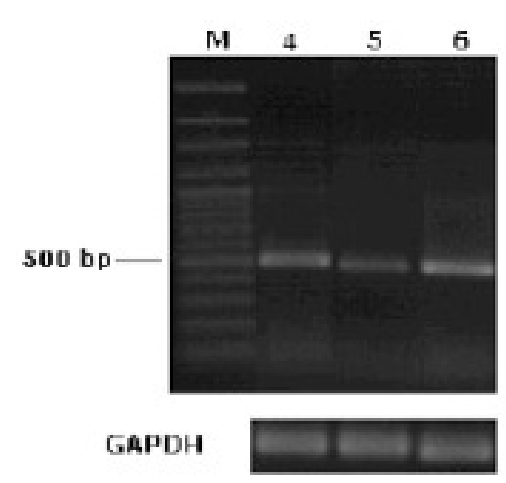

Fig. 2. $A P E /$ Ref-1 mRNA expression in acute and chronic spinal cord injury groups with and without ENSC therapy. (a) RT-PCR products, separated and visualized by agarose gel electrophoresis, representing APE/Ref-1 mRNA levels (520 bp) in lanes 1 - acute sham-operated, 2 - acute SCI, 3 acute SCI + ENSC therapy 4 - chronic sham-operated, 5. Chronic SCI, 6 chronic SCI + ENSC therapy groups. M: 100 bp DNA Ladder molecular size marker, (b) Values are presented as the ratio between the target mRNA and the corresponding GAPDH mRNA in acute and chronic groups $(*, a, p<0.01$ and $\# \mathrm{p}<0.05)$.

(b)

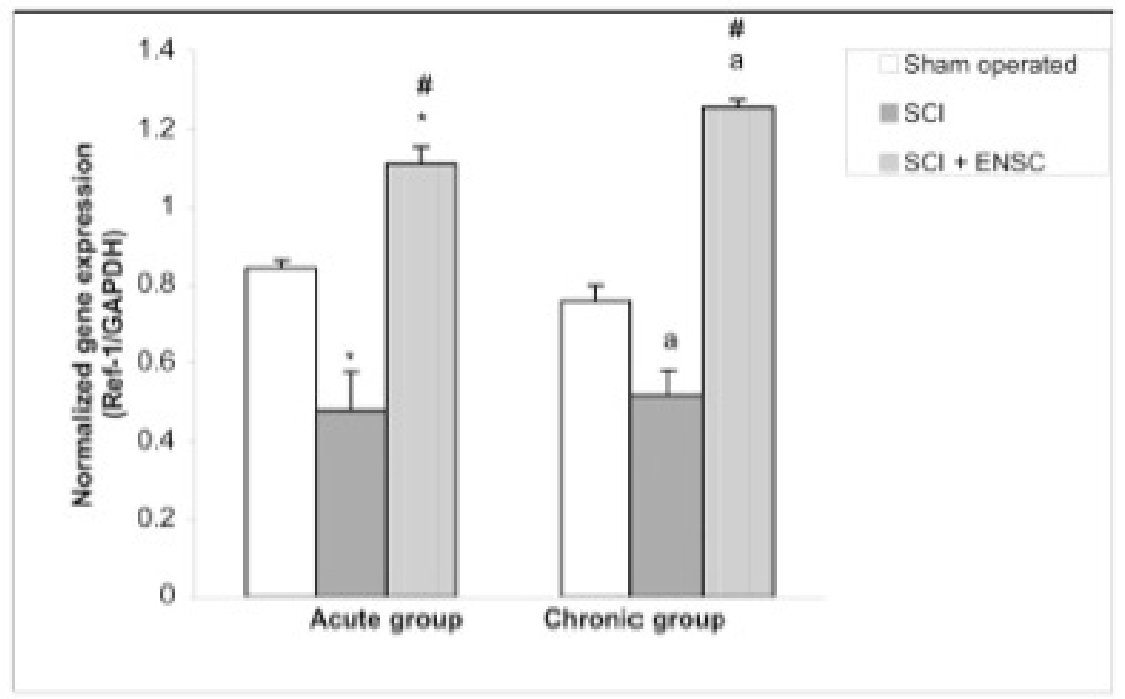

such as APE/Ref-1. APE/Ref-1 is suggested to play a central role in base excision repair by $3^{\prime}-\mathrm{OH}$ primer for synthesis of DNA after all types of oxidative damage. However, APE/Ref-1 expression is reduced after the severe SCI studied. Kawase et al. (1999) have suggested that ROS might have an important role in the reduction of APE/Ref-1. Although the mechanism of APE/Ref-1 reduction after trauma is not clearly known, free oxygen radicals can reduce the expression of APE/Ref-1. Our results showed that comet scores were strongly correlated with APE/Ref-1 in caudal sections of acute and chronic injured spinal cords.

After ENSC therapy comet scores (Tail-DNA \%, TL and TM) clearly decreased, but APE/Ref-1 expression levels increased. The ENSC treatment reduced oxidation of DNA, presumably due to the reduction of free radical formation as a result of oxidative stress blockade. Indirectly this treatment also permitted DNA repair to be sustained in cells at all sections of the spinal cord. As expected, we observed a similar improvement in caudal DNA damage after ENSC therapy for the acute and chronic SCI groups. The significantly higher improvement in the chronic ENSC therapy group, compared to the acute ENSC group, might be due to the improvement of secondary damage events, such as edema, hemorrhage, inflammatory reaction, ischemia and oxidative stress.

In conclusion, we have shown that APE/Ref-1 decreased after acute and chronic SCI in the caudal section. After the ENSC therapy, the oxidative DNA damage improved and elevated APE/Ref-1 expression levels. Further examinations are necessary to elucidate the relationship between the potential antioxidant effects of stem cell therapy and APE/Ref-1 expression levels.

\section{Conflict of Interest}

There is no conflict of interest. 


\section{References}

AZBILL RD, MU X, BRUCE-KELLER AJ, MATTSON MP, SPRINGER JE: Impaired mitochondrial function, oxidative stress and altered antioxidant enzyme activities following traumatic spinal cord injury. Brain Res 765: 283-290, 1997.

BAMBAKIDIS NC, THEODORE N, NAKAJI P, HARVEY A, SONNTAG VK, PREUL MC, MILLER RH: Endogenous stem cell proliferation after central nervous system injury: alternative therapeutic options. Neurosurg Focus 19: E1, 2005.

BAO F, CHEN Y, DEKABAN GA, WEAVER LC: An anti-CD11d integrin antibody reduces cyclooxygenase-2 expression and protein and DNA oxidation after spinal cord injury in rats. J Neurochem 90: 1194-1204, 2004.

BEAL MF: Aging, energy, and oxidative stress in neurodegenerative diseases. Ann Neurol 38: 357-366, 1995.

BOHR VA, ANSON RM: Mitochondrial DNA repair pathways. J Bioenerg Biomembr 31: 391-398, 1999.

CHOMCZYNSKI P: A reagent for the single-step simultaneous isolation of RNA, DNA and proteins from cell and tissue samples. Biotechniques 15: 532-534, 1993.

CHOPP M, CHAN PH, HSU CY, CHEUNG ME, JACOBS TP: DNA damage and repair in central nervous system injury: National Institute of Neurological Disorders and Stroke Workshop Summary. Stroke 27: 363-369, 1996.

HAN SS, KANG DY, MUJTABA T, RAO MS, FISCHER I: Grafted lineage-restricted precursors differentiate exclusively into neurons in the adult spinal cord. Exp Neurol 177: 360-375, 2002.

JUURLINK BH, PATERSON PG: Review of oxidative stress in brain and spinal cord injury: suggestions for pharmacological and nutritional management strategies. J Spinal Cord Med 21: 309-334, 1998.

KAWASE M, FUJIMURA M, MORITA-FUJIMURA Y, CHAN PH: Reduction of apurinic/apyrimidinic endonuclease expression after transient global cerebral ischemia in rats: implication of the failure of DNA repair in neuronal apoptosis. Stroke 30: 441-448, 1999.

KIM D, SCHALLERT T, LIU Y, BROWARAK T, NAYERI N, TESSLER A, FISCHER I, MURRAY M: Transplantation of genetically modified fibroblasts expressing BDNF in adult rats with a subtotal hemisection improves specific motor and sensory functions. Neurorehabil Neural Repair 15: 141-150, 2001.

LEE YS, SINDHU RK, LIN CY, EHDAIE A, LIN VW, VAZIRI ND: Effects of nerve graft on nitric oxide synthase, NAD(P)H oxidase, and antioxidant enzymes in chronic spinal cord injury. Free Radic Biol Med 36: 330-339, 2004.

LEPORE AC, FISCHER I: Lineage-restricted neural precursors survive, migrate, and differentiate following transplantation into the injured adult spinal cord. Exp Neurol 194: 230-242, 2005.

LEPORE AC, HAN SS, TYLER-POLSZ CJ, CAI J, RAO MS, FISCHER I: Differential fate of multipotent and lineage-restricted neural precursors following transplantation into the adult CNS. Neuron Glia Biol 1: 113-126, 2004.

LINDAHL T, NYBERG B: Rate of depurination of native deoxyribonucleic acid. Biochemistry 11: 3610-3618, 1972.

LIU Y, KIM D, HIMES BT, CHOW SY, SCHALLERT T, MURRAY M, TESSLER A, FISCHER I: Transplants of fibroblasts genetically modified to express BDNF promote regeneration of adult rat rubrospinal axons and recovery of forelimb function. J Neurosci 19: 4370-4387, 1999.

LOEB LA, PRESTON BD: Mutagenesis by apurinic/apyrimidinic sites. Annu Rev Genet 20: 201-230, 1986.

MURRAY M, KIM D, LIU Y, TOBIAS C, TESSLER A, FISCHER I: Transplantation of genetically modified cells contributes to repair and recovery from spinal injury. Brain Res Brain Res Rev 40: 292-300, 2002.

NADIN SB, VARGAS-ROIG LM, CIOCCA DR: A silver staining method for single-cell gel assay. J Histochem Cytochem 49: 1183-1186, 2001.

RAMANA CV, BOLDOGH I, IZUMI T, MITRA S: Activation of apurinic/apyrimidinic endonuclease in human cells by reactive oxygen species and its correlation with their adaptive response to genotoxicity of free radicals. Proc Natl Acad Sci USA 95: 5061-5066, 1998.

SCHULTZ SS: Adult stem cell application in spinal cord injury. Curr Drug Targets 6: 63-73, 2005.

SCHWAB JM, PHILIPPE P, MONNIER PP, SCHLUESENER HJ, CONDRAD S, BESCHORNER R, CHEN L, MERMANN R, MUELLER BK: Central nervous system injury-induced repulsive guidance molecule expression in the adult human brain. Arch Neurol 62: 1561-1568, 2005. 
SHIMAZAKI T: Biology and clinical application of neural stem cells. Horm Res 60 (Suppl 3): 1-9, 2003.

SINGH NP, MCCOY MT, TICE RR, SCHNEIDER EL: A simple technique for quantitation of low levels of DNA damage in individual cells. Exp Cell Res 175: 184-191, 1988.

THORNWALL M, SHARMA HS, GORDH T, SJOQUIST PO, NYBERG F: Substance P endopeptidase activity in the rat spinal cord following injury: influence of the new anti-oxidant compound H 290/51. Acta Neurochir Suppl 70: 212-215, 1997.

VAZIRI ND, LEE YS, LIN CY, LIN VW, SINDHU RK: NAD(P)H oxidase, superoxide dismutase, catalase, glutathione peroxidase and nitric oxide synthase expression in subacute spinal cord injury. Brain Res 995: 76-83, 2004.

XU M, WAI-CHEONG YIP G, GAN LT, NG YK: Distinct roles of oxidative stress and antioxidants in the nucleus dorsalis and red nucleus following spinal cord hemisection. Brain Res 1055: 137-142, 2005. 